www.pasosonline.org

\title{
A utilização das redes sociais na perspetiva das empresas de turismo em espaço rural
}

\author{
Ana Oliveira* \\ Instituto Politécnico de Viana do Castelo (Portugal) \\ Alexandra Isabela Correia** \\ Instituto Politécnico de Viana do Castelo (Portugal) \\ Carlos Fernandes*** \\ Instituto Politécnico de Viana do Castelo (Portugal)
}

\begin{abstract}
Resumo: O presente artigo identifica as perceções e comportamentos por parte dos proprietários/gerentes das pequenas e médias empresas turísticas (PMETs) de alojamento em relação à utilização das redes sociais, no presente e no futuro. Tendo por base uma perspetiva qualitativa, foram realizadas nove entrevistas semiestruturadas aos proprietários/gerentes das PMTEs sediadas na região Minho-Lima, no norte de Portugal. A redução de custos com a aquisição de novos clientes, assim como o aumento da credibilidade e a melhoria da reputação das empresas são algumas das principais vantagens percecionadas. O Facebook destaca-se como sendo a rede social mais utilizada, dada a maior facilidade de se conseguir alcançar um mercado mais amplo de forma fácil, rápida, e sem custos, considerando, essencialmente, o elevado número de utilizadores. No entanto, este estudo demonstra também que existe um forte desconhecimento de como podem as redes sociais ser, em particular o Facebook, utilizadas de forma eficiente e eficaz. Este artigo contribui para um maior conhecimento sobre o potencial das redes sociais para as empresas turísticas em contexto rural. O conhecimento destas perceções é importante para que possa identificar iniciativas e estratégias de comunicação adequadas à realidade das empresas, incentivando, assim, uma maior e mais eficaz utilização das redes sociais.
\end{abstract}

Palavras-chave: Redes Sociais, Facebook, Turismo Rural, PMEs, Perceções, Análise de Conteúdo, Entrevista

The use of social networks in the perspective of rural tourism companies

Abstract: This paper identifies the perceptions and behaviours of owners/ managers of rural small and medium-sized tourism enterprises (SMTEs) regarding the use of social networks at the present time and in the future. Based on a qualitative perspective, nine semi-structured interviews were conducted with owners / managers of SMTEs based in the Minho-Lima region of northern Portugal. The costs reduction in acquiring new customers, improving credibility and corporate reputation are some of the main perceived advantages. Facebook stands out as being the most used social network, given the greater ease of achieving a broader market in an easy and fast way, essentially considering the high number of users. However, this paper also demonstrates that there is a strong lack of knowledge of how social networks, particularly Facebook, can be used in efficiently and effectively way. This paper seeks to contribute to a better understanding of the potential of social networks for tourism businesses operating in the rural context. Understanding these perceptions is important to identify initiatives and communication strategies appropriated to enterprises reality, contributing to encourage a greater and more effective use of social networks.

Keywords: Social Networks, Facebook, Rural Tourism, SMEs, Perceptions, Content Analysis, Interview

Mestre em Turismo, Inovação e Desenvolvimento IPVC; anavoliveira@ipvc.pt

** Doutoramento em Turismo pela Bournemouth University (UK); acorreia@estg.ipvc.pt

*** Professor Adjunto IPVC; cfernandes@estg.ipvc.pt 


\section{Introdução}

As redes sociais, resultado dos avanços tecnológicos a que se tem assistido nos últimos anos, apresentam importantes vantagens para as empresas (Michaelidou, Christodoulides, \& Theofania, 2011; Hays, John \& Buhalis, 2013; Lopes, Abrantes, \& Kastenholz, 2014), em particular para a sua comunicação (Boyd \& Ellison, 2007), sendo, hoje, considerada uma ferramenta fundamental para a competitividade das empresas (Hays, et al., 2013; Fernandes, Belo \& Castela, 2016). Os custos associados à utilização destas ferramentas são reduzidos (Doyon-Roch, 2016), quando comparados com os meios de comunicação tradicionais utilizados também pelas empresas.

No entanto, e apesar do potencial para as empresas, as redes sociais acarretam também desafios, pois a sua utilização pressupõe conhecimentos técnicos, tempo e investimentos financeiros, (Kaplan \& Haenlein, 2010, Vásquez \& Escamilla, 2014). Esta questão é particularmente importante para as PMETs, dadas as suas características. As PMETs, tendo um papel crucial na criação de emprego e desenvolvimento das regiões (Kastenhloz, 2003; Keller, 2004; Buhalis \& Peters, 2006), estão, muitas delas, sujeitas a constrangimentos associados à sazonalidade, sediadas em espaço rural, sendo, na sua maioria de cariz familiar (Irvine \& Anderson, 2004), e enfrentam inúmeros desafios na sua comunicação e no alcance de novos mercados, devido a limitações, quer ao nível dos recursos financeiros, quer ao nível dos recursos humanos (North \& Smallbone, 1996).

Para as empresas, as redes sociais podem ser simultaneamente uma oportunidade (Beier \& Wagner, 2016), proporcionando uma aproximação maior com o cliente através da possibilidade de contacto direto em tempo real, bem como um desafio, incitando a encontrar soluções de rentabilização em prol do sucesso dos seus negócios (Kaplan \& Haenlein, 2010). Desta forma e apesar do reconhecido potencial das redes sociais para as PME (Fernandes et al., 2016), existe ainda pouca informação sobre as razões da sua utilização por parte das PMEs (Beier \& Wagner, 2016) a sua adoção e utilização, de forma eficaz, tem sido lenta e/ou inexistente (Schaffer, 2013), sendo, por isso, relevante o estudo dos fatores que levam à sua utilização (Danhil \& Marzuki \& Langgat \& Fabeil, 2014) também por parte das PMET, sendo, por isso, importante perceber-se se as PMET utilizam, ou não, as redes sociai, porquê e de que forma. É, pois, neste contexto, que o presente artigo tem como objetivo identificar as perceções, atitudes e comportamentos por parte dos gerentes das PMETs (alojamento), localizadas em contexto rural rurais, em relação à utilização das redes sociais, no presente e no futuro.

Este artigo encontra-se organizado em seis diferentes secções, iniciando-se pela presente Introdução na qual é apresentada uma breve contextualização sobre as redes sociais assim como o objetivo deste trabalho; de seguida, surge o enquadramento teórico dos principais temas em análise; numa terceira seção carateriza-se a região do Minho-Lima, sendo apresentado o enquadramento territorial, a realidade socioeconómica, caracterização da oferta turística na região ao nível do Turismo em Espaço Rural (TER); na secção subsequente, é explicada a metodologia adotada e na quinta seção, são apresentados e discutidos os resultados obtidos. Por fim, são apresentadas as conclusões e implicações, bem como as recomendações para futuros estudos.

\section{Enquadramento Teórico}

Embora na bibliografia não seja evidente uma definição formalmente aceite para o termo "redes sociais", são vários os autores que procuram desmistificar este conceito. Uma das explicações mais completas é a apresentada por Boyd \& Ellison (2007), na qual as redes sociais são entendidas como uma ferramenta baseada na internet que permite aos utilizadores, em primeiro lugar, construir um perfil público ou semipúblico dentro de um sistema limitado, criar ligações com outros utilizadores e, por último, visualizar as conexões estabelecidas dentro do mesmo sistema. A questão das conexões é um dos elementos chave nesta definição, que aliás, é também destacada por outros autores, como por exemplo, Lisbôa \& Coutinho (2010), quando referem que as redes sociais são um conjunto de conexões através das quais as informações circulam. Estas informações podem assumir formatos diferentes, designadamente, imagens, músicas, vídeos ou opiniões, consoante o objetivo do utilizador (Hays et al., 2013).

Para o setor turístico, as informações partilhadas nas redes sociais, nomeadamente experiências, opiniões e fotografias sobre as suas viagens e experiências, assumem um papel fundamental, na medida em que podem ser decisivas no momento da tomada de decisão e compra, minimizando os riscos de aquisição de determinado serviço turístico. Os comentários realizados e publicados por visitantes são largamente valorizados por outros utilizadores, considerados como mais confiáveis, em detrimento das 
publicações feitas pela própria empresa (Fotis, Buhalis, \& Rossides, 2011; Schaffer, 2013; Lopes et al., 2014; Zeng \& Gerritsen, 2014).

Desta forma, as redes sociais estão a alterar o paradigma da informação e comunicação (Leung \& Law \& van Hoof \& Buhalis, 2013) apresentando claras oportunidades para a competitividade das empresas turísticas (Hays et al., 2013). Se, por um lado, os consumidores estão a alterar o modo como acedem à informação, como planeiam as suas viagens e como partilham as experiências de viagem, as empresas, por outro lado, utilizam, as redes sociais como um meio para apoiar as suas atividades de marketing, nomeadamente para identificar novas necessidades, para avaliar o grau de satisfação face a determinado serviço, para implementar melhorias, e para promover a sua oferta (Lopes et al., 2004). O processo comunicacional abandonou, assim o seu o caráter unidirecional, no qual as empresas controlavam de forma fácil o fluxo de informações com o cliente, para se tornar num processo bidirecional, onde é tão relevante o conteúdo e a forma do que é transmitido pela empresa ao cliente, como o feedback que recebe do mercado (Drury, 2008; Soares, Pinho, \& Nobre, 2012).

A presença das empresas turísticas neste meio online revela-se uma mais-valia para os seus negócios, face à multiplicidade de oportunidades que as redes sociais apresentam dada a proximidade com os seus atuais e/ou potenciais clientes (Fernandes et al., 2016), permitindo-lhes partilhar e discutir conteúdos (Kaplan \& Haenlein, 2010; Doyon-Roch, 2016), dada facilidade de criar comunidades online com os utilizadores da rede social (Lisbôa \& Coutinho, 2010; Vásquez \& Escamilla, 2014).

As redes sociais apresentam-se, assim, como um canal de marketing mais eficaz na promoção e comercialização de produtos e/ou serviços turísticos (Leung et al. 2013). Permitem a implementação de estratégias de marketing diferenciadas, focadas não só na comercialização, como também na criação de relações interativas com os utilizadores (Fotis et al., 2011; Zeng \& Gerritsen, 2014). Para além disso, permite-lhes estar a par das atividades desenvolvidas pela concorrência e pelo mercado em geral, interagir com os atuais e/ou potenciais turistas, entender as suas expectativas, e ainda monitorizar a imagem da empresa (Fernandes et al., 2016). Possibilita, de igual modo, a interação direta e de forma dinâmica com o turista, procurando estimular o diálogo através da partilha de fotografias, vídeos ou experiências sobre determinado destino ou produto turístico (Boyd \& Ellison, 2007; Buhalis \& Jun, 2011; Michaelidou et al., 2011; Hays, et al., 2013).

A utilização das redes sociais implica custos inferiores quando comparadas com outros meios de comunicação, sendo inclusivamente gratuitas a um nível de utilização mais simples (Buhalis \& Jun, 2011). Todavia, o uso das redes sociais a um nível mais profissional constitui um desafio para as empresas, pois requer investimentos financeiros (Buhalis \& Law, 2008; Michaelidou et al., 2011), conhecimentos técnicos e tempo (Kaplan \& Haenlein, 2010). De facto, a limitação de recursos propicia poucas oportunidades para contratar profissionais qualificados e promover formação para os colaboradores. As PMET ficam, assim, dependentes das competências pessoais e entusiasmo dos seus colaboradores e, portanto, enfrentam desvantagens competitivas quando comparadas com as grandes empresas que possuem mais meios para atrair recursos humanos especializados (Buhalis, 1996). No caso particular das PMET sediadas em espaço rural, os desafios para o desenvolvimento de negócios nestas áreas são ainda mais acentuados devido às caraterísticas típicas dos destinos rurais, tais como: a sazonalidade e as baixas taxas de ocupação (Irvine \& Anderson, 2004). Muitas empresas são de carater familiar, não possuem conhecimentos e competências de gestão suficientes para implementar planos estratégicos de forma a reduzir os efeitos negativos da sazonalidade (North \& Smallbone, 1996; Irvine \& Anderson, 2004).

Por outro lado, é sabido que a utilização das redes sociais exige novas formas de pensar (Kaplan \& Haenlein, 2010), o que para muitas empresas constitui uma barreira significativa, dada a falta de conhecimento ou inexperiência neste contexto (Michaelidou et al., 2011). Para além destes aspetos, e embora as empresas tenham autonomia sobre o tipo de conteúdos que são partilhados e com que periocidade, a verdade é que enfrentam desafios acrescidos em controlar toda a informação partilhada pelos utilizadores e/ou consumidores relacionada com a sua atividade e/ou marca. O consumidor possui total liberdade para partilhar informação, positiva ou negativa, sobre qualquer produto/serviço, baseado, ou não, nas suas próprias experiências, que futuramente poderá influenciar o processo de decisão de compra de outros potenciais clientes (Mangold \& Faulds, 2009).

A abordagem do tema das redes sociais aplicadas ao contexto turístico na bibliografia é relativamente recente (Hays et al., 2013). No entanto, e apesar do reconhecimento quanto às potencialidades das redes sociais para as PMET, particularmente como ferramenta de comunicação, com custos mais reduzidos face aos meios de comunicação tradicionais (Doyon-Roch, 2016), a verdade é que muitas delas têm sido lentas a adotá-las, devido, quer à falta de dinheiro e/ou tempo, quer em virtude das opiniões negativas sobre a sua utilidade (Schaffer, 2013). Face a este contexto, este estudo visa explorar em mais detalhe 
as perceções, atitudes e comportamentos por parte dos proprietários/gerentes das PMETs (alojamento), localizadas em contexto rural, em relação à utilização das redes sociais, no presente e no futuro.

\section{A Região Minho-Lima}

A região Minho-Lima, marcadamente rural, engloba uma ampla área de património natural, na qual está integrada uma grande parte do território do Parque Nacional da Peneda-Gerês (CIM Alto Minho a), 2013). A região, localizada no extremo Noroeste de Portugal, abrange dez municípios do distrito de Viana do Castelo: Arcos de Valdevez, Caminha, Melgaço, Monção, Paredes de Coura, Ponte da Barca, Ponte de Lima, Valença, Viana do Castelo e Vila Nova de Cerveira (INE, 2014).

\section{Figura 3.1 - Mapa da região Minho-Lima}

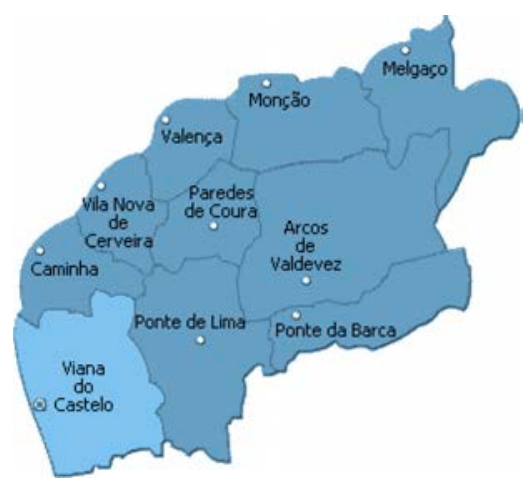

Fonte: CIM Alto Minho a) (2013)

À semelhança do que acontece com as áreas rurais, em geral, o Minho-Lima é fortemente afetado pelo êxodo da população para as zonas urbanas, sendo procurado como uma opção de residência secundária (CIM Alto Minho a), 2013). Porém, numa perspetiva turística, esta região apresenta um elevado potencial ao nível da procura e da oferta. No panorama turístico nacional, o Minho-Lima destaca-se pela elevada concentração de empreendimentos TER e pela diversidade de recursos endógenos, sejam eles naturais, patrimoniais e/ou culturais (CIM Alto Minho a), 2013), o que faz com que esta região apresente uma forte aptidão para a prática de turismo de natureza, turismo em espaço rural e enoturismo, por exemplo. Estas atividades são cada vez mais importantes no desenvolvimento da região, considerando que promovem a diversificação da economia rural e impulsionam a criação de infraestruturas que beneficiam turistas e contribuem, simultaneamente, para a qualidade de vida dos residentes (Vareiro, 2008; Eusébio \& Kastenholz, 2010).

De acordo com os dados disponibilizados pelo Turismo de Portugal I.P. (2016), existem 1626 empreendimentos turísticos TER em Portugal, sendo que $42 \%$ dessa oferta está localizada na região Norte (NUT II) e 30\% da oferta desta região está concentrada no Minho - Lima (NUT III). Destaca-se o elevado número de Casas de Campo (165 unidades), que representa mais de metade da oferta existente (79,7\%), seguindo-se o Agroturismo (36 unidades), e este representa 17,3\% da oferta, e por fim, os hotéis rurais surgem com menor expressão (6 unidades), representando apenas $3 \%$ da oferta no Minho-Lima.

\section{Metodologia}

Tendo presente o objetivo do estudo, optou-se pela análise das empresas classificados como Empreendimentos de Turismo TER existentes na região Minho-Lima, nomeadamente, Casas de Campo, Agroturismo e Hotéis Rurais.

A listagem de todas estas empresas foi obtida através do Registo Nacional de Empreendimentos Turísticos (RNET), disponibilizado pelo Turismo de Portugal (2015), dada de realização deste estudo, juntamente com a informação disponibilizada pelas câmaras municipais através das suas páginas web. 
Numa primeira fase, foi realizada uma análise de conteúdo das empresas TER nas redes sociais, o que permitiu, por um lado, verificar se, e de que forma, as redes sociais estavam a ser utilizadas pelas empresas em questão, e por outro lado, identificar as empresas presentes nas redes e com uma dinâmica relevante para este estudo.

Para efeitos desta análise, foram consideradas as redes Facebook, Google+, LinkedIn, Instagram e Twitter, por serem das mais utilizadas a nível mundial, de acordo com o número de utilizadores ativos em maio de 2016 (Statastics Brain, 2016), e por serem aquelas que concedem às empresas autonomia e/ou controlo para se promoverem no meio online de forma simples, rápida e com custos reduzidos face a outros meios de promoção (Xiang \& Gretzel, 2010; Zeng \& Gerritsen, 2014).

A tabela que se segue (Tabela 4.1) mostra um conjunto de métricas mensuráveis, que servem como um ponto de partida para analisar a dinâmica da empresa nas redes sociais (Hoffman \& Fodor, 2010; Honigman, 2013) e que permitem avaliar o alcance dos esforços comunicacionais nas redes sociais. Estas métricas foram utilizadas na análise de conteúdo de todas as empresas TER na região Minho-Lima. (Honigman, 2013)

Tabela 4.1 - Métricas usadas na Análise das Redes Sociais

\begin{tabular}{lll}
\hline Rede Social & Notoriedade da Marca & Envolvimento com a Empresa \\
\hline Facebook & Número de gostos & Número de interações (comentários, gostos e partilhas) \\
& Número de avaliações & $\begin{array}{l}\text { Número de publicações } \\
\text { Frequência de publicações } \\
\text { Taxa de envolvimento } \\
\text { Hashtags }\end{array}$ \\
\hline Google+ & Número de seguidores & Número de interações (comentários, +1's, partilhas) \\
& Número de & Frequência de publicações \\
& visualizações & Número de gostos \\
LinkedIn & Número de seguidores & Número de comentários \\
& & Recomendações \\
\hline Instragram & Número de seguidores & Número de gostos \\
& & Número de comentários \\
& Frequência de publicações \\
& Hashtags \\
\hline Twitter & Número de tweets & Número de seguidores \\
& Número de seguidores & Número de retweets \\
& Frequência de publicações \\
& Hashtags \\
\hline
\end{tabular}

Fonte: Adaptado de Hoffman \& Fodor (2010) e Honigman (2013)

As métricas analisadas foram: taxa de envolvimento, Hashtags e frequência das publicações.

A métrica "Taxa de envolvimento", no caso específico do Facebook, permite conhecer o nível de envolvimento dos fãs da página com o conteúdo publicado. Desta forma, é possível identificar que tipos de conteúdos geram maior envolvimento por parte dos fãs/seguidores da página. Uma alternativa rápida assenta na relação entre o número interações total, isto é, gostos, comentários e partilhas de todas as publicações, e o número total de gostos da página (Simply Measured, 2014). Como tal, foram contabilizadas todas as interações da página entre a data da primeira e da última publicação, até ao dia em que foi feita a análise (9, 10 e 11 de dezembro de 2014). Quando o resultado obtido apresenta valores acima de $1 \%$, a taxa de envolvimento é considerada boa e o número de interações é superior ao número de gostos. Quando os valores obtidos estão entre 0,5\% e 0,99\%, é considerada uma taxa razoável e o número de interações não difere muito do número de gostos. Já uma taxa abaixo dos 0,5\% pode significar que o tipo de conteúdo publicado não é o expectável ou não é de grande interesse, por exemplo (Simply Measured, 2014).

Relativamente às Hashtags, são palavras-chave precedidas pelo símbolo \#, que as empresas podem incluir nas suas publicações, permitindo organizar as informações por temas, e consequentemente 
aumentar a notoriedade da empresa nas diferentes redes sociais. Honigman (2013) defende que esta é uma métrica importante para avaliar o envolvimento do público-alvo com a empresa.

No que se refere ao cálculo da frequência das publicações, foi tida em consideração o número de publicações na semana da data desta análise, ou seja, entre 4 e 11 de dezembro de 2014, e foi posteriormente dividido o número de dias da semana.

Foram também analisados os conteúdos de imagem, vídeo e texto publicados nas páginas das empresas nas redes sociais, com o intuito de perceber que tipos de conteúdos são publicados frequentemente e quais geram maior interatividade com o público-alvo. Para além disso, foram analisados os conteúdos das respostas de forma a identificar aspetos positivos e/ou negativos.

Como resultado desta primeira análise, o Facebook destacou-se claramente como a rede mais utilizada (ex. número de gostos, interações, publicações, tempo de presença de cada empresa empresas nesta rede e a taxa de envolvimento). As restantes redes têm ainda uma utilização muito reduzida. A síntese da análise das restantes redes sociais será apresentada no Subcapítulo 5.2.

Por esta razão, O Facebook foi a rede social explorada com maior detalhe comparativamente às restantes redes em relação a cada empresa, tendo sido abordados aspetos como o apresentados detalhadamente na Tabela 4.1. Para além de ser a rede social mais utilizada pelas empresas TER da região Minho-Lima, este destaque dado ao Facebook é também justificado pelo fato esta ser a rede social mais utilizada mundialmente (Statastics Brain, 2016).

Após esta análise de conteúdo, a entrevista semiestruturada foi a técnica utilizada para a recolha de dados, devido ao elevado grau de flexibilidade na exploração das questões, não exigindo uma ordem rígida das questões (Finn, Elliott-White, \& Walton, 2000).

Optou-se por recorrer a técnicas de amostragem não probabilísticas, nomeadamente a uma amostragem por conveniência (Quivy \& Campenhoudt, 1998; Vicente, Reis, \& Ferrão, 2001; Moreira, 2007). Esta amostra não é representativa da população em estudo, pelo que os resultados e as conclusões obtidas se aplicam somente à amostra em causa, não podendo ser extrapolados com confiança para a população-alvo (Hill \& Hill, 2009, p. 50). Foram realizadas nove entrevistas, considerando-se ser uma amostra suficiente tendo em vista o objetivo definido, e tendo por base também a dimensão da amostra utilizada em estudos anteriores com caraterísticas semelhantes (Mizrachi, 2014). (1998)

Durante o processo de seleção das empresas TER, para além de estarem presentes nas redes sociais, era necessário que as páginas das empresas estivessem atualizadas e apresentassem uma dinâmica relevante. Como tal, a todas as empresas TER presentes nas redes sociais foram aplicados critérios específicos, nomeadamente: existência de publicações no Facebook pelo menos duas vezes por semana; taxa de envolvimento no Facebook superior a 0,5\%; número de gostos no Facebook superior a 1000; presença no Instagram; e por fim presença no Google+. Concluída esta etapa, foram identificadas vinte e duas empresas TER, das quais nove Casas de Campo, dez unidades de Agroturismo e três Hotéis Rurais, dispersas pela região Minho-Lima. No entanto, pelas razões supracitadas referentes à dimensão da amostra considerou-se que nove empresas seria um número suficiente para a concretização do objetivo, e simultaneamente, abranger todas as tipologias. Assim sendo foram selecionadas quatro Casas de Campo, quatro unidades de Agroturismo e um Hotel Rural.

As entrevistas foram realizadas aos proprietários e/ou gerentes entre os dias 21 e 28 de abril de 2015, nas próprias empresas, com duração, em médica, de 45 minutos.

As questões que compõem a entrevista subdividem-se em quatro grupos: utilização das redes sociais pelas empresas, resultados e desafios destas ferramentas para as empresas TER, caraterização da empresa e caraterização do entrevistado, por forma a identificar as atitudes e comportamentos dos proprietários/gerentes relativamente à utilização das redes sociais. O Facebook foi a rede mais explorada pelas razões explicadas anteriormente.

Após a recolha dos dados, procedeu-se à pré-análise, exploração do material e tratamentos dos resultados Bardin (1977), na primeira quinzena de maio de 2015. Depois de transcritas as entrevistas, foi feita uma divisão por temáticas apresentadas no capítulo seguinte.

\section{Apresentação e Discussão dos Resultados}

Em primeiro lugar, apresentam-se os dados resultantes da análise de conteúdo das empresas TER nas diferentes redes sociais, com ênfase para a rede social Facebook. De seguida, são apresentados e discutidos os resultados que refletem a análise das entrevistas realizadas na primeira quinzena de maio de 2015. 


\subsection{Análise de conteúdo}

Constatou-se que num universo de 184 empresas TER na região, 58\% estão presentes nas redes sociais, sendo que oitenta são Casas de Campo, vinte e duas são unidades de Agroturismo e cinco são Hotéis Rurais. Isto demonstra que existe a preocupação por parte destas empresas em utilizar as redes sociais, em particular, no que respeita à promoção da sua oferta. Este resultado vem corroborar o que já havia sido identificado na bibliografia, nomeadamente de que existe já um cuidado por parte das PMET no que concerne à utilização das redes sociais, o que pode ser explicado pelas características da indústria turística e pelo elevado risco envolvido na aquisição de um serviço turístico, uma vez que a qualidade só é percebida após o seu consumo (Buhalis \& Jun, 2011; Hays, et al., 2013; Lopes et al., 2014).

No entanto, embora estas empresas TER $(n=107 ; 58 \%)$ possuam uma página nalguma rede social, verificou-se que muitas das páginas estão desatualizadas, sem qualquer atividade ao nível de publicações até à data da análise. No caso particular do Facebook, a inexistência de publicações e o número reduzido de gostos da página refletiu-se numa taxa reduzida de envolvimento. Este resultado demonstra que as empresas poderão claramente melhorar o seu desempenho ao publicar conteúdos de forma regular e procurar manter a página atualizada.

O Facebook é a rede mais utilizada em todas as tipologias de alojamento empresas ( $\mathrm{n}=80 ; 75 \%)$, seguindo-se a rede social Google+ $(\mathrm{n}=67 ; 63 \%)$. Com menor expressão surgem as redes Twitter, LinkedIn, e Instagram.

De entre as empresas presentes no Facebook $(n=80)$, diferenciam-se as que possuem um perfil pessoal daquelas que possuem um perfil institucional. Desta forma, verificou-se que a maior parte das empresas TER, $(\mathrm{n}=59 ; 74 \%)$ possui uma página com características profissionais. Para efeitos deste estudo, foram consideradas as 59 empresas com uma página institucional no Facebook, uma vez que este é um dos elementos-chave para uma presença online eficaz. Para além disso, os critérios/métricas utilizados pelo investigador aplicam-se exclusivamente às páginas de caráter empresarial.

Os resultados que se seguem serão apresentados em valor numérico dado se tratar de valores pequenos, facilitando, desta forma a compreensão do leitor.

\subsection{As Empresas TER no Facebook}

O Gráfico 5.1 mostra que 35 das empresas com uma página institucional está presente no Facebook há mais de um ano.

\section{Gráfico 5.1 - Tempo de Presença no Facebook}

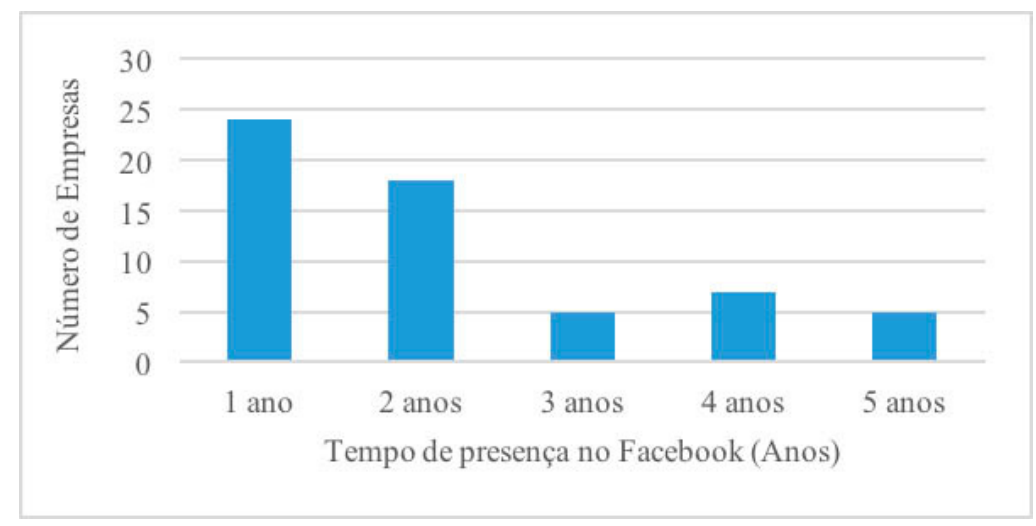

Fonte: Elaboração própria

No Gráfico 5.2, relacionado com o tempo de atividade e o número de gostos nas páginas de Facebook, verifica-se que numa grande parte das empresas o número de gostos é inferior a 1000. Existem duas situações que se destacam, uma pela negativa, tendo a empresa apenas 3 gostos, e uma pela positiva, em que a empresa tem 8934 gostos.

Para além disso, verifica-se (Gráfico 5.2.) que, no caso das empresas ativas no Facebook há dois ou menos anos (37), 34 destas empresas apresentam um número de gostos inferior a 1000. Em relação às 
empresas ativas no Facebook há mais de dois anos, na sua maioria (9), o número de gostos continua a ser inferior a 1000 .

\section{Gráfico 5.2 - Tempo de Presença e o Número de Gostos no Facebook}

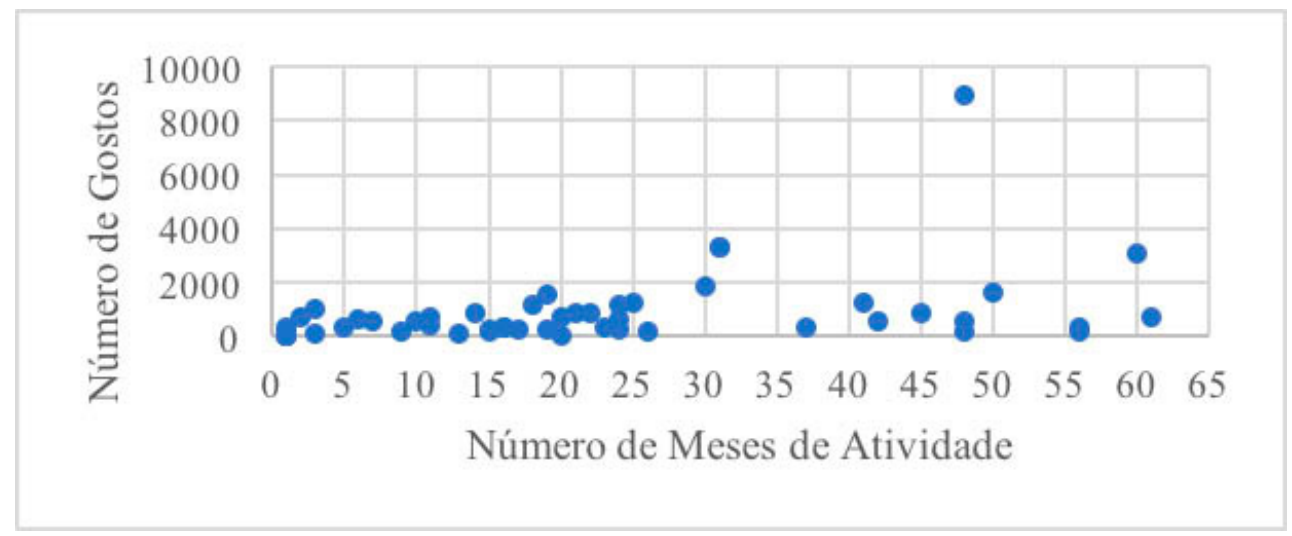

Fonte: Elaboração própria

No que se refere aos valores da taxa de envolvimento, como é possível constatar no Gráfico 5.6, metade das empresas (29) analisadas apresentam uma taxa abaixo dos 0,5\%. Nesta análise, um elevado número de gostos não é sinónimo de uma taxa de envolvimento elevada, visto que esta taxa é facilmente influenciada, quer pela quantidade como pela qualidade das publicações, tal como explicado anteriormente.

\section{Gráfico 5.3 - Taxa de Envolvimento no Facebook}

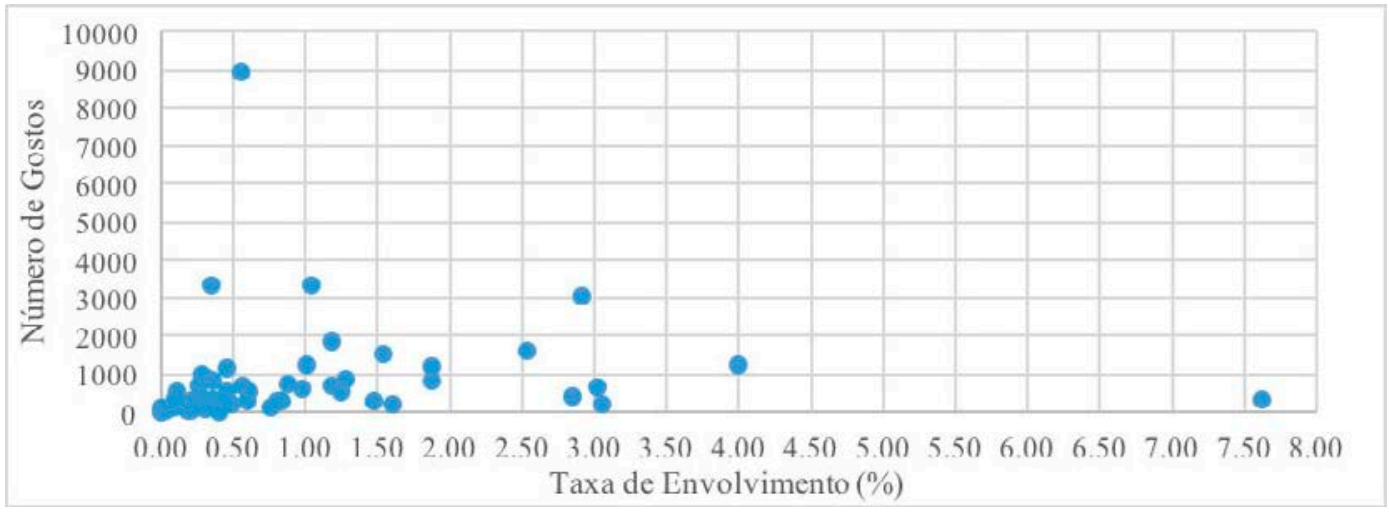

Fonte: Elaboração própria

De salientar que duas empresas, nas quais o número de gostos é igual a 3312 e 8934, estão presentes no Facebook há mais de dois anos, mas as suas taxas de envolvimento não ultrapassam os $0,35 \%$ e os $0,55 \%$, respetivamente. São 18 as empresas que possuem uma taxa de envolvimento superior a $1 \%$, nas quais o número de interações é ligeiramente superior ao número de gostos. No entanto, destacam-se três casos onde este número é, em média, três vezes mais que o número de gostos. De acordo com o Gráfico 5.4, verifica-se que à medida que o número de publicações aumenta, o número de interações tende a aumentar também. 


\section{Gráfico 5.4 - Relação entre o Número de Publicações e Interações no Facebook}

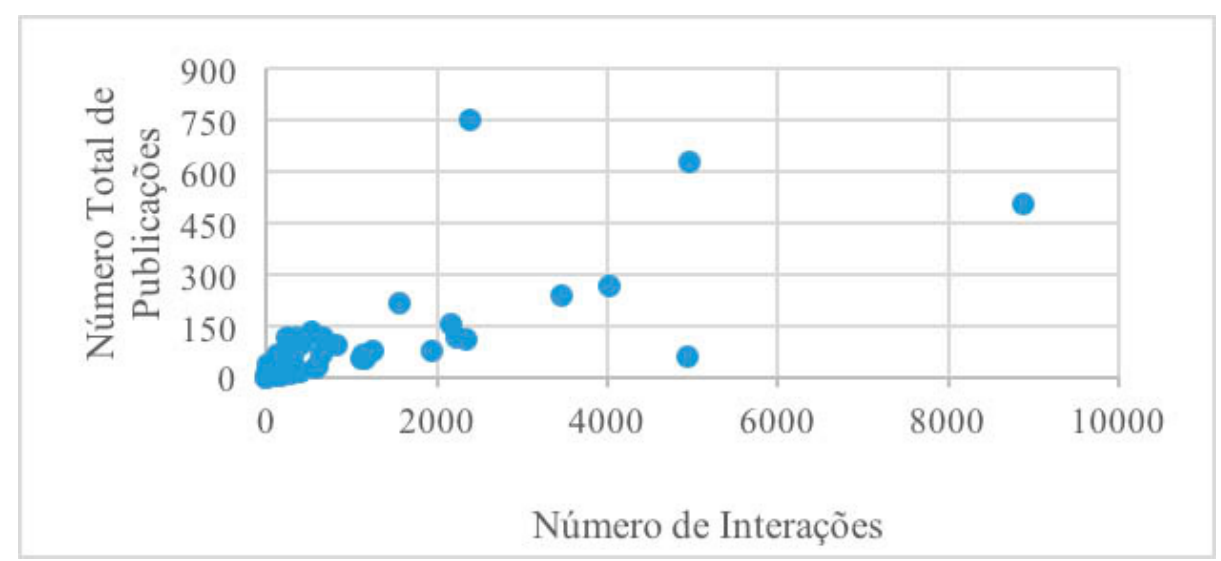

Fonte: Elaboração própria

No que se refere à tipologia de conteúdos, conclui-se que cerca de $80 \%$ dos conteúdos publicados são imagens, seguindo-se o texto com $13 \%$, e por fim o conteúdo de vídeo com apenas $8 \%$.

Perante a análise do Gráfico 5.5, constata-se que independentemente do número de meses de atividade, o número total de publicações na maioria das empresas estudadas concentra-se abaixo das 150. Porém, existem seis situações que não se enquadram nesta maioria. Três delas possuem menos de 25 meses de atividade e apresentam um número total de publicações entre 216 e 267 , publicando em média cerca de seis posts mensalmente; outras três empresas com mais de quarenta e cinco meses de atividade, nas quais o total de publicações varia entre 501 e 751, publicando em média catorze posts por mês.

\section{Gráfico 5.5 - Relação entre o Tempo de Presença e o Número de Publicações no Facebook}

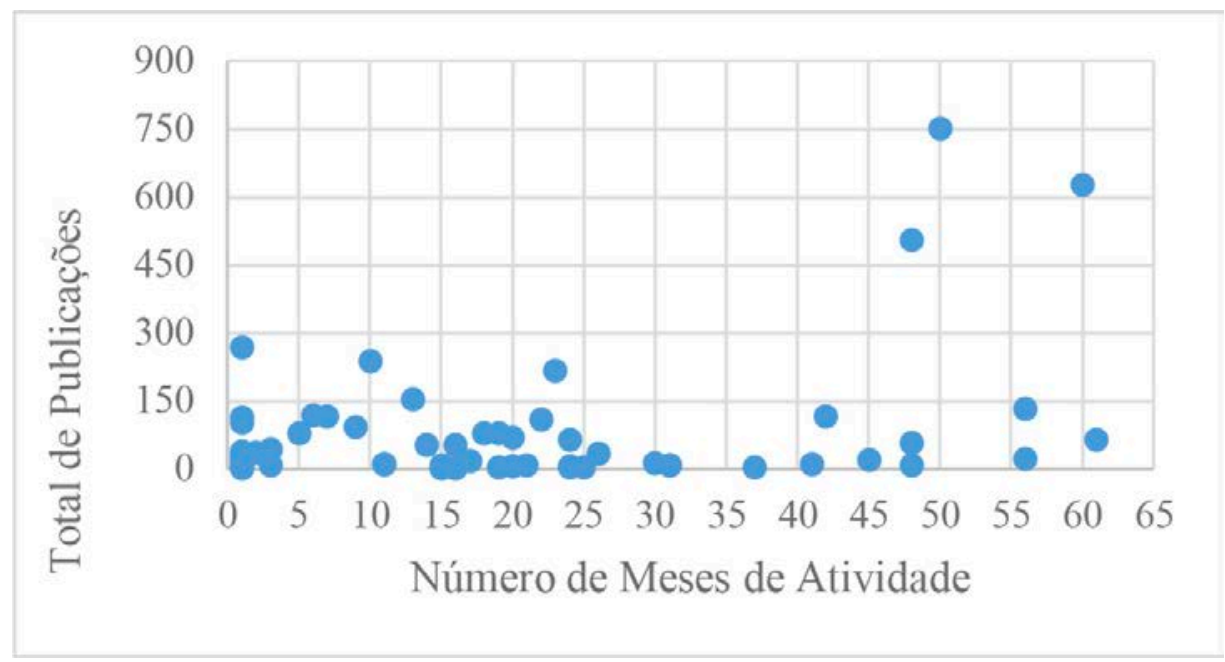

Fonte: Elaboração Própria

Relativamente a aspetos qualitativos, designadamente presença de tópicos de discussão, utilização de hashtags e hiperligações para outros websites, constatou-se que nenhuma das empresas estudadas apresenta tópicos suscetíveis de lançar temas de discussão ou que procurem conhecer os desejos dos seguidores da página. Mais ainda, a presença de hashtags é praticamente inexistente. 


\subsection{As Empresas TER nas Restantes Redes Sociais}

Tal como já foi referido anteriormente, a rede social Google+ surge em segundo lugar no que toca à utilização por parte das PMET TER analisadas. Entre as 67 empresas presentes nesta rede, 38 destas empresas não possui qualquer publicação, verificando-se apenas a existência de uma página com os contactos da mesma e uma aplicação para efetuar reservas.

No que se refere à rede social Twitter, são 14 as empresas com uma conta ativa. Analisando detalhadamente, 10 destas empresas publicaram tweets, e inseriram imagens ou vídeos na sua página. De salientar que três destas empresas têm a conta Facebook e Twitter interligada, pelo que as publicações feitas no Facebook aparecem simultaneamente no Twitter. Das restantes quatro empresas, embora não se tenha registado qualquer atividade ao nível de publicações, três delas possuem até quatro seguidores.

No que diz respeito ao Instagram, apenas quatro das empresas estão presentes nesta rede. O número de seguidores varia entre 8 e 216 , e total de publicações varia entre 3 e 27 .

Por fim, nove das empresas TER possuem uma conta no LinkedIn. Porém não se verificou qualquer atividade, existe unicamente uma página criada e na maioria das situações surge o nome do proprietário em primeiro lugar.

A utilização das redes Google+, Twitter, Linkedin e Instagram é irrelevante, quando comparada com a dinâmica de algumas empresas TER no Facebook. Estes resultados comprovam o impacto que o Facebook tem no quotidiano das empresas turísticas, dada a sua influência no comportamento dos consumidores, tanto na escolha do destino ou do alojamento, como no como no planeamento de uma viagem (Schaffer, 2013; Lopes et al, 2014; Zeng \& Gerritsen, 2014).

\subsection{Perceções e Comportamentos das Empresas TER no Facebook}

Os dados que se seguem resultam da análise das entrevistas. A análise recai sobre o Facebook pelas razões já mencionadas. $\mathrm{Na}$ amostra selecionada (nove), cinco das empresas TER estão presentes no mercado do alojamento turístico há menos de cinco anos, sendo que três são unidades de Agroturismo e duas são Casas de Campo. Ao nível dos respondentes, cinco são do género masculino e quatro do género feminino, todos detentores de formação superior, quase todos (oito) com idades compreendidas entre 40 e 60 anos e com outra atividade profissional, para além da exploração do empreendimento turístico.

O Facebook é a rede social utilizada por todas as empresas inquiridas, sendo que para seis destas, a página possui entre 1000 e 5000 gostos e uma taxa de envolvimento superior a 1\%. Os respondentes assumem que a presença nesta rede revela-se como uma excelente oportunidade de promoção para a empresa e, simultaneamente, permite alcançar um mercado mais amplo de forma fácil, rápida, e sem custos (face ao elevado número de utilizadores que esta rede possui), e manter o contacto com os hóspedes. Para além disso, é importante no aumento do trafego gerado do Facebook para o website.

Estas razões apontadas pelos inquiridos coincidem com as citadas por alguns autores, tendo sido, ainda, referido que através destas ferramentas as empresas podem também recolher informações sobre o mercado em que estão inseridas (Rayman-Bacchus \& Molina., 2001; Zeng \& Gerritsen, 2014; Beier \& Wagner, 2016).

Os inquiridos descrevem o Facebook como uma ferramenta simples e bastante intuitiva ao nível do seu backoffice. Todavia, dois dos entrevistados alertam para os "entraves dissimulados" que o Facebook coloca aos gerentes, nomeadamente a redução do alcance orgânico das publicações, isto é, sem qualquer investimento financeiro, com o intuito de os "obrigar" a investir, caso pretendam um alcance maior das suas partilhas.

\subsubsection{Os Conteúdos Partilhados no Facebook}

De facto, a publicação de fotografias é a principal atividade realizada no Facebook por todos os inquiridos e, simultaneamente, aquela que gera maior número interações. Esta partilha engloba tanto fotos da empresa, como também imagens consideradas relevantes para atrair potenciais clientes a visitar a página. Outra das atividades mais realizadas por alguns dos gerentes (seis no total) é a partilha de eventos que possam ser interessantes para os seus mercados-alvo. Para além destas atividades, três dos gerentes também indicaram que realizam uma análise da concorrência atual e potencial através do Facebook, alegando a importância de acompanhar o que os concorrentes fazem, com o intuito de evoluir e anteciparem-se na oferta de serviços ao mercado.

Ainda sobre a partilha de imagens, os respondentes apontam três caraterísticas para que seja bem-sucedida, a criatividade, a qualidade, e/ou resolução da imagem. Ressalvam que a fotografia partilhada deverá ser próxima da realidade, isenta de tratamentos de imagem exagerados, evitando assim que o hóspede se sinta defraudado entre aquilo que viu na página do Facebook e a realidade. Sobre este tema, 
um dos inquiridos acrescentou que, habitualmente, publica fotografias dos seus hóspedes no decorrer de atividades desportivas durante a estadia, porém sublinha o cuidado a fotografar os hóspedes de forma a não serem facilmente identificáveis. Esta prática e cuidado são fundamentais, dado que, por um lado, a privacidade dos hóspedes é assegurada, e por outro, são um meio para atrair os hóspedes a visitar a página da empresa após a sua estada, e eventualmente, comentarem e partilharem as fotografias com a sua rede de amigos.

São inúmeras as atividades que podem ser desenvolvidas nas redes sociais, tais como: partilhar conteúdos, interagir com os fãs da página, criar grupos de amigos com quem podem partilhar os conteúdos, visualizar conexões feitas por outros utilizadores dentro do mesmo sistema, analisar a concorrência, e ainda monitorizar a imagem do empreendimento online (Boyd \& Ellison, 2007; Hays, et al., 2013; Lopes et al., 2014). No entanto, todos os respondentes se dedicam unicamente à partilha de fotografias, e apenas três deles afirmaram analisar também a concorrência. Isto demonstra que apesar de estarem presentes nas redes sociais, a maioria dos respondentes desconhece como rentabilizar essa presença em prol do sucesso do negócio. Na verdade, nenhum dos respondentes possui formação adicional em áreas como o marketing digital, redes sociais ou comunicação online.

Os conteúdos partilhados, tanto pela empresa como por qualquer utilizador na página, são fundamentais para a tomada de decisão de clientes, assim como também influenciarão a construção da identidade online de um empreendimento turístico a longo prazo (Xiang \& Gretzel, 2010; Zeng \& Gerritsen, 2014). Neste aspeto, concluiu-se que os respondentes estão cientes da importância da publicação de conteúdos gráficos e da resposta a comentários positivos e/ou negativos publicados na página da empresa. Em cada publicação é importante a existência de uma imagem associada à mesma, seja ela um evento, um texto ou uma hiperligação para outro website. Porém, no que se refere aos conteúdos de vídeo, estes são quase inexistentes nas páginas do Facebook das empresas. Crê-se que uma das principais tendências nas redes socias será a inclusão de vídeos curtos de forma a aumentar a interatividade dos fãs.

Para além disso, outro aspeto que contribuirá para aumentar a interatividade dos fãs da página, é o equilíbrio entre o conteúdo publicado por qualquer utilizador e o conteúdo publicado pela empresa (Kerpen, 2011). Esta é uma recomendação fundamental, contudo, ao nível das empresas TER entrevistadas, somente um dos respondentes se mostrou atento às publicações que são feitas por ambas as partes. Para que a comunicação através das redes sociais produza os efeitos desejados, esta tem de ser bidirecional, sendo um dos aspetos que as distinguem dos demais meios de comunicação tradicionais.

\subsubsection{A Gestão de Comentários no Facebook}

A gestão de comentários é um dos desafios que todos os respondentes enfrentam com a presença da empresa no Facebook. No entanto, por norma, todos os inquiridos respondem através de um comentário ou simplesmente através da colocação de um gosto. Apenas uma das empresas entrevistadas foi alvo de comentários menos positivos na sua página do Facebook. Face a este tipo de ocorrência, o responsável procura, em primeiro lugar, identificar o sujeito através do cruzamento do nome no Facebook com a base de dados dos hóspedes da empresa, e em caso positivo, procede ao envio um email ou uma mensagem privada no Facebook, procurando perceber o fundamento do comentário partilhado e a razão pela qual não relatou o sucedido durante a estadia ou aquando a realização do check-out. Quando são comentários menos positivos provenientes de algum sujeito que nunca esteve hospedado no empreendimento turístico, o gerente adverte que, primeiramente é necessário identificar a origem da crítica. Por vezes, são sujeitos que agem por pura maldade sem qualquer fundamento, mas também pode ser a concorrência camuflada a tentar denegrir a imagem da empresa.

Para além dos comentários, o Facebook dispõe de uma seção para que os hóspedes, ou não, possam avaliar a empresa com estrelas de um a cinco. Três dos entrevistados relataram que, frequentemente recebem avaliações de uma estrela de alguém que nunca esteve hospedado no empreendimento. Segundo eles, este tipo situações ocorre porque alguns dos utilizadores da página desconhecem o objetivo daquela seção e a lógica das estrelas, uma vez que, para eles uma estrela seria sinónimo de "muito bom". Dois destes entrevistados, optam por interagir com os utilizadores através de comentários, agradecendo a visita do potencial cliente à página do Facebook e convidam-no a visitar o espaço pessoalmente na expetativa dele melhorar a sua pontuação. Para finalizar, um dos entrevistados rematou que este tipo de situações influencia o ranking geral da avaliação da empresa no Facebook. No entanto, salientou também a importância das pessoas interagirem na rede social, através de comentários, partilhas ou gostos, argumentando que, se tal não ocorresse, todos os esforços e investimentos na comunicação seriam em vão. Completou esta ideia justificando que a comunicação em qualquer rede social deverá ser bidirecional e não teria interesse em ter uma página sem qualquer feedback, seja ele positivo ou 
negativo. Os comentários que os hóspedes publicam têm um peso muito importante, já que para os clientes (atuais e potenciais) são vistos como uma fonte de informação credível.

\subsubsection{Os Investimentos Financeiros no Facebook}

Tal como já foi referido nesta análise, o Facebook tende a limitar o alcance orgânico das publicações para que os gestores das páginas façam investimentos financeiros nesta rede. Sobre esta temática, as respostas obtidas subdividem-se entre aqueles que já o fizeram (cinco) e os que não fizeram (quatro), sendo diversos os motivos apontados.

Abordando, em primeiro lugar, as empresas que já investiram no Facebook, conclui-se que apenas duas das empresas estão satisfeitas com os resultados obtidos. Dos inquiridos agradados, um deles revelou que a definição dos critérios do anúncio é essencial para o sucesso da campanha, sendo que opta por fazer investimentos unicamente em determinados tipos de publicações, geralmente, fotografias com potencial ao nível da qualidade de imagem ou promoções direcionadas exclusivamente para os clientes do Facebook. Acrescentou ainda que, os investimentos financeiros no Facebook levam a que a imagem da empresa apareça frequentemente no mural de potenciais clientes, dando origem a um aumento do número de gostos da página, assim como a um aumento do trafego gerado do Facebook para o website da empresa.

Quanto aos inquiridos insatisfeitos com os investimentos feitos no Facebook, as razões apontadas são variadas. Um destes respondentes investiu numa campanha direcionada exclusivamente para o mercado espanhol, mas os resultados ficaram aquém do que seria expetável. Outro dos respondentes insatisfeitos comentou já investiu na promoção da página, mas acredita que esta alternativa não seja a melhor para a promoção da empresa. Fê-lo com o intuito de testar, investindo uma quantia irrelevante, porém verificou que enquanto existe investimento é visível um aumento do número de gostos e de visualizações, findo esse investimento volta tudo a estagnar. Relativamente ao terceiro respondente insatisfeito, referiu aquando da realização de investimentos financeiros notou um retorno ao nível das reservas, embora pouco significativo. No entanto, e devido à atual conjuntura económica, optou por não investir no Facebook, mas sim noutras páginas mais direcionadas e preparadas para a promoção do turismo rural.

No que diz respeito aos entrevistados que não despendem qualquer valor monetário para promover os seus empreendimentos no Facebook, a maioria mencionou que ainda não sente essa necessidade, visto que sem investimentos conseguem obter boas taxas de ocupação. Para dois destes gerentes, os investimentos financeiros não fazem parte da estratégia de comunicação da empresa, argumentando que, no caso de uma das empresas as verbas destinadas à promoção são canalizadas para outros meios de promoção online, e na outra situação as razões estão relacionadas com a atual situação financeira da empresa. Para os outros dois gerentes, a realização de investimentos é uma questão a considerar no futuro.

Em termos dos investimentos financeiros no Facebook, é unânime entre os respondentes que são obtidos melhores resultados quando existe um investimento, ao nível do aumento da visibilidade da página e do número de reservas, embora este último com menor relevância. Isto corrobora o que foi mencionado por vários autores no enquadramento teórico, que apesar do acesso a estas ferramentas ser gratuito, o uso a um nível mais profissional com resultados mensuráveis requer um investimento financeiro (Buhalis \& Law, 2008; Buhalis \& Jun, 2011; Michaelidou et al., 2011).

\subsubsection{A Avaliação da Presença no Facebook}

Relativamente à avaliação da empresa no Facebook, cinco dos inquiridos recorrem aos dados estatísticos disponibilizados pela própria rede, utilizando estes dados para iniciativas futuras, nomeadamente, identificar potenciais clientes e novos mercados, avaliar o sucesso das suas publicações e identificar possíveis falhas na comunicação. Isto vem comprovar uma das recomendações proposta por Evans \& McKee (2010) e Kaplan \& Haenlein (2010), ouvir/acompanhar o que é publicado nas redes sociais é a chave para compreender o que o consumidor partilha sobre a empresa, e permite às empresas detetar facilmente irregularidades inerentes à sua atividade.

Os restantes quatro gerentes não fazem qualquer tipo de avaliação, desvalorizam a sua importância, mas admitem que podem estar a falhar e a desperdiçar informação relevante para o sucesso da empresa.

Quando abordados sobre a relação da presença no Facebook e os resultados efetivos que daí advêm, a maioria admite que, de alguma forma, notaram efeitos positivos. Todos os respondentes se mostraram bastante satisfeitos com a presença da empresa, tendo havido um aumento de visibilidade da mesma e do número de visualizações geradas a partir do Facebook para o website e para outras páginas da 
internet em que as empresas estejam presentes. Para além disso, a presença no Facebook e noutras redes sociais tem sido fundamental para aumentar a credibilidade da empresa na internet, aumentando assim as probabilidades de, sem investir dinheiro, a empresa surgir sempre em primeiro nas pesquisas do Google. No entanto, em termos do número de reservas, os resultados são pouco expressivos, referindo a dificuldade em quantificar quantos gostos na página se convertem numa reserva.

Por fim e quando questionados sobre a possibilidade de aderirem a outras redes sociais no futuro, os entrevistados mostraram-se bastante recetivos, mas, simultaneamente, preocupados com a questão do tempo necessário para dedicar a cada uma das redes.

Redes sociais como o Twitter, o Instagram e o Pinterest fazem parte do leque de opções de alguns dos respondentes. Somente dois dos respondentes não mencionaram nenhuma rede social, frisaram apenas que o objetivo dos seus empreendimentos é expandir no meio online. Para isso pretendem aderir ao maior número possível de redes, aumentando assim as probabilidades do cliente se cruzar com informação sobre a empresa na internet.

\section{Conclusões e Recomendações}

Na bibliografia, a temática das redes sociais aplicadas ao contexto turístico é uma área ainda pouco estudada (Hays et al., 2013), pelo que, este estudo veio contribuir para reflexão sobre o potencial destas ferramentas para as empresas turísticas localizadas em espaço rural e para a obtenção de dados sobre as perceções e comportamentos relativamente à utilização das redes sociais.

Este estudo mostrou que o Facebook é a rede social mais utilizada pelas empresas TER da região Minho-Lima, tendo sido considerado pelos entrevistados como um excelente meio para as empresas TER se promover, alcançar um mercado mais amplo, e sem custos (face ao elevado número de utilizadores que esta rede possui), manter o contacto com os hóspedes, e ainda gerar trafego para o website da empresa. De facto, é percecionado que estas ferramentas apresentam custos inferiores face a outros meios de comunicação, e que permitem às empresas um contacto mais próximo com os seus atuais e/ ou potenciais clientes. Portanto, face aos múltiplos constrangimentos que estas empresas enfrentam (ex. a dimensão reduzida e de carater familiar das empresas, a limitação de recursos financeiros e a falta de profissionais qualificados), a integração das redes sociais possibilitará novas oportunidades às empresas TER para competir no mercado, e ainda acompanhar as atividades da sua concorrência.

Constatou-se, ainda, que a comunicação destas empresas TER não se baseia em nenhuma estratégia comunicacional previamente definida. As suas publicações são realizadas à medida que surge alguma necessidade, não havendo uma periocidade habitual para publicar. Para além disso, os dados obtidos mostram que o impacto do Facebook no número de reservas não é significativo, sendo difícil por exemplo quantificar quantos gostos da página se convertem numa reserva.

Todavia, verificou-se que, ainda assim, todos os respondentes se mostraram satisfeitos com a presença das empresas TER no Facebook. Constatou-se que a presença no Facebook e noutras redes sociais tem sido fundamental para aumentar a credibilidade do empreendimento na web, aumentando assim as probabilidades do espaço surgir em primeiro nas pesquisas do Google sem investir dinheiro.

Em termos gerais, mais de metade das empresas TER estão presentes em pelo menos uma rede social, o que demonstra interesse por parte dos seus gerentes em estar a par das novas tendências. No caso particular do Facebook, a inexistência de publicações e o número reduzido de gostos da página refletiu-se numa taxa reduzida de envolvimento. Conclui-se que apesar de estarem presentes nas redes sociais, existe ainda um forte desconhecimento de como pode o Facebook e as restantes redes socais serem utilizadas de forma eficaz.

Estes resultados permitem perceber melhor se as PMET utilizam, ou não, as redes sociais, porquê e como, podendo levar à identificação de estratégias de comunicação adequadas à realidade das PMET, bem como a identificação de iniciativas e/ou ações que possam incentivar uma maior e mais eficaz utilização das redes sociais, por um lado, e facilitar a operacionalização das estratégias identificadas, contribuindo para uma maior competitividade destas empresas.

Para finalizar, em trabalhos futuros seria interessante explorar o impacto e potencialidades de outras redes sociais na comunicação das PMET. Para além disso, este tema apresenta-se com potencial de crescimento no panorama académico, e por isso, seria benéfico desenvolver mais estudos a nível nacional sobre a presença das empresas turísticas em espaço rural nas redes sociais; procurando, por um lado, analisar o comportamento da procura turística através destes meios, e por outro, as respostas das empresas. 
Por outro lado, e apesar da presença nas redes sociais ser gratuita, conseguir resultados efetivos através dessa presença requer a existência de um website institucional e/ou um investimento financeiro por parte das empresas. Assim sendo, seria interessante investigar a importância que o website institucional assume no sucesso da comunicação dos empreendimentos turísticos presentes nas redes sociais, bem como o impacto que os investimentos financeiros nas redes sociais possam ter na conversão de clientes, também através dos websites.

As limitações deste estudo estão relacionadas com o número de entrevistas. Apesar de estas entrevistas terem explorado as perceções e comportamentos dos proprietários/gerentes das empresas em detalhe, sugere-se que em estudos futuros se procure realizar um maior número de entrevistas.

\section{Bibliografia}

Bardin, L.

1977. Análise de Conteúdo. Lisboa: Edições 70.

Batikas, M., Bavel, R., Martin, A., \& Maghiros, I.

2013. Use of Social Media by European SMEs. Luxembourg: Publications Office of the European Union.

Beier, Michael and Wagner, Kerstin, "Social Media Adoption: Barriers To The Strategic Use Of Social

Media In Smes"

2016. Research Papers. Paper 100 http://aisel.aisnet.org/ecis2016_rp/100

Boyd, D., \& Ellison, N.

2007. Social Network Sites: Definition, History, and Scholarship. Journal of Computer-Mediated Communication, 13, $210-230$.

Buhalis, D.

1996. Enhancing the Competitiveness of Small and Medium-sized Tourism Enterprises. International Journal of Electronic Commerce, 6, 1-6.

Buhalis, D., \& Jun, S.

2011. E-Tourism. Contemporary Tourism Reviews, 1-38.

Buhalis, D., \& Law, R.

2008. Progress in Information Technology and Tourism Management: 20 years on and 10 years after the Internet-The State of eTourism Research. Tourism Management, 609 - 623.

Buhalis, D., \& Peters, M.

2006. SMEs in Tourism. Em C. Costa, \& D. Buhalis, Tourism Management Dynamics: Trends, Management and Tool (pp. 116-129). Elsevier Butterworth-Heinemann.

CIM Alto Minho

2013. Estratégia \& Plano Global de Ação "Alto Minho 2020". Viana do Castelo: Comunidade Intermunicipal do Minho-Lima;

Dahnil, M. I., Marzuki, K. M., Langgat, J., \& Fabeil, N. F.

2014. Factors Influencing SMEs Adoption of Social Media Marketing. Procedia - Social and Behavioral Sciences, 148, 119-126. http://doi.org/10.1016/j.sbspro.2014.07.025

Doyon-Roch, J.

2016. Social Media to Support Collaboration in the Product Life Cycle of SMEs. Quebec: Université de Sherbrooke. Tese para a obtenção do grau de Mestre em Gestão do Comércio Eletrónico.

Drury, G.

2008. Opinion piece: Social media: Should marketers engage and how can it be done effectively? Journal of Direct, Data and Digital Marketing Practice, 274-277.

Eusébio, C., \& Kastenholz, E.

2010. Quem Procura o Turismo no Espaço Rural? Especificidades do Mercado da Região Centro de Portugal. Em E. Figueiredo, E. Kastenholz, M. Eusébio, Gomes, M.C. Carneiro, M.J. Batista, P., \&; Valente, S., Mundos Rurais em Portugal - Múltiplos Olhares, Múltiplos Futuros (pp. 334-347). Aveiro: Universidade de Aveiro.

Evans, D., \& McKee, J.

2010. Social Media Marketing: The Next Generation of Business Engagement. Wiley Publishing, Inc. Fernandes, S., Belo, A., Castela, G.

2016. Social Network Enterprise Behaviors and Patterns in SMEs: Lessons from a Portuguese Local Community Centered round the Tourism Industry. Technology in Society, 44, 15 - 22. 
Finn, M., Elliott-White, M., \& Walton, M.

2000. Tourism \& Leisure Research Methods: Data Collection, Analysis and Interpretation. Harlow:

Pearson Longman.

Fotis, J., Buhalis, D., \& Rossides, N.

2011. Social Media Impact onHoliday Travel Planning: The Case of the Russianand the FSU Markets.

International Journal of Online Marketing, 1-19.

Hays, S., John Page, S., \& Buhalis, D.

2013. Social Media as a Destination Marketing Tool: Its Use by National Tourism Organisations. Current Issues in Tourism, 16, 211-239.

Hill, M., \& Hill, A.

2009. Investigação por Questionário. Lisboa: Edições Ś́labo.

Hoffman, D., \& Fodor , M.

2010. Can you measure the ROI of your Social Media Marketing? MIT Sloan Management Review, 41-49. Honigman, B.

2013. How to Effectively Measure Your Instagram Efforts. Obtido de http://blog.sumall.com/: http:// blog.sumall.com/journal/how-to-effectively-measure-your-instagram-efforts-2.html

INE.

2015. Anuário Estatístico da Região Norte - 2014. Lisboa: Instituto Nacional de Estatística.

Irvine, W., \& Anderson, A.

2004. Small tourist firms in rural areas: agility, vulnerability and survival. International Journal of

Entrepreneurial Behaviour \& Research, 10, 229-246.

Kaplan, A., \& Haenlein, M.

2010. Users of the world, unite! The challenges and opportunities of Social Media. Business Horizons, 59-68.

Kastenholz, E.

2003. A Gestão da Procura Turística como Instrumento Estratégico no Desenvolvimento de Destinos

Rurais. Em O. Simões, \& A. Cristovão, TERN - Turismo em Espaços Rurais e Naturais (pp. 203 - 216).

Coimbra: Edições IPC.

Keller, P.

2004. The Future of Small and Medium Size Enterprises in Tourism. 54th AIEST-Kongress: The Future of SME's in Tourism - International Association of Scientific Experts in Tourism. Petra, Jordánia: International Association of Scientific Experts in Tourism (AIEST).

Kerpen, D.

2011. Likeable Social Media: How to Delight Your Costumers, Create an Irresistible Brand and Be Generally Amazing on Facebook (and Other Social Networks). Estados Unidos da América: Publicações McGraw-Hill.

Leung, D., Law, R., van Hoof, H., \& Buhalis, D.

2013. Social Media in Tourism and Hospitality: A Literature Review. Journal of Travel \& Tourism Marketing, 30 (1-2), 3-22. http://doi.org/10.1080/10548408.2013.750919

Lisboa, E., \& Coutinho, C.

2010. Design and Validation of an Analysis Grid of Social Networks (Virtual Communities). Proceedings of Society for Information Technology \& Teacher Education International Conference (pp. 162-169). San Diego, Estados Unidos da América: Association for the Advancement of Computing in Education (AACE).

Lopes, R., Abrantes, J., \& Kastenholz, E.

2014. Innovation, tourism and social networks. Revista Turismo e Desenvolvimento, 151-154.

Mangold, W., \& Faulds, D.

2009. Social media: The new hybrid element of the promotion mix. Business Horizons , 357-365.

Meltwater.

2014. Like Alyzer. Obtido de http://www.likealyzer.com/about

Michaelidou, N., Christodoulides, G., \& Theofania, N.

2011. Usage, Barriers and Measurement of Social Media Marketing: An Exploratory Investigation of Small and Medium B2B Brands. Industrial Marketing Management, 40, 1153 - 1159.

Mizrachi, I.

2014. Facebook Adoption by Australian Small Tourism Enterprises (STEs): Business Requirements and User Perceptions. Melbourne: The College of Business Victoria University. 
Moreira, C.

2007. Teorias e Práticas de Investigação. Lisboa: Instituto Superior de Ciências Sociais e Politicas.

Morisson, A., \& Thomas, R.

1999. The future of small firms in the hospitality industry. International Journal of Contemporary

Hospitality Management, 11, 148-154.

Ndekwa, A. G., \& Katunzi, T. M.

2016. Small and Medium Tourist Enterprises and Social Media Adoption : Empirical Evidence from

Tanzanian Tourism Sector. International Journal of Business and Management, 11 (4), 71-80. http://

doi.org/10.5539/ijbm.v11n4p71

North, D., \& Smallbone, D.

1996. Small Business Development in Remote Rural Areas: the Example of Mature Manufacturing

Firms in Northern England. Journal of Rural Studies, 12, 151-167.

Quivy, R., \& Campenhoudt, L.

1998. Manual de Investigação em Ciências Sociais (2. ${ }^{a}$ Edição ed.). Lisboa: Gravisa.

Rayman-Bacchus, L., \& Molina, A.

2001. Internet-Based Tourism Services: Business Issues and Trends. Futures, 33, 589 - 605.

Schaffer, V.

2013. Overcoming Social Media Barriers for Small Business. 26th Annual SEAANZ Conference Proceedings

(pp. 1-12). Sydney: Small Enterprise Association of Australia and New Zealand .

Simply Measured.

2014. Facebook Metrics Defined: Engagement Rate. Obtido de Simply Measured: http://goo.gl/ycDLeZ Soares, A., Pinho, J., \& Nobre, H.

2012. From Social to Marketing Interactions: The Role of Social Networks. Journal of Transnational Management, 45-62.

Statastics Brain.

2016. Facebook Statistics. Obtido em http://www.statisticbrain.com/facebook-statistics/

Turismo de Portugal.

2016. Registo Nacional dos Empreendimentos Turísticos. Obtido de https://goo.gl/PSxv92

Vareiro, L.

2008. Turismo como estratégia integradora dos recursos locais: o caso da NUT III Minho-Lima. Braga:

Universidade do Minho - Tese para a obtenção do grau de Doutor.

Vásquez, G., Escamilla, E.

2014. Best practice in the use of social networks marketing strategy as in SME. Procedia - Social and

Behavioral Sciences 148, $533-542$.

Vicente, P., Reis, E., \& Ferrão, F.

2001. Sondagens: A amostragem como factor decisivo de qualidade. Lisboa: Edições Sílabo.

Xiang, Z., \& Gretzel , U.

2010. Role of Social Media in Online Travel Information Search. Tourism Management, 31, 179 - 188.

Zeng, B., \& Gerritsen, R.

2014. What do we know about social media in tourism? A review. Tourism Management. Perspectives, 27-36. 